\title{
MODELLING THE CARBONATED CONCRETE REALKALIZATION
}

\author{
Mariusz Jaśniok ${ }^{1}$, Adam Zybura ${ }^{2}$ \\ Dept of Building Structures, Silesian University of Technology, Akademicka str. 5, 44-100 Gliwice, Poland. \\ E-mail: ${ }^{1}$ mariusz.jasniok@polsl.pl; ${ }^{2}$ adam.zybura@polsl.pl \\ Received 12 Aug 2008, accepted 29 Mar 2009
}

\begin{abstract}
The presented model of carbonated concrete realkalization is compiled on the basis of the multi-component medium theory equations. The process equations have been obtained from an analysis of the partial equations of mass, electric charge, momentum, energy, and entropy inequality. The experimental testing reported is related to a theoretical model which determines changes of ion concentrations in the pore solution of the cover, as a result of the realkalization. On the basis of the test results, the process equations have been simplified and formally transformed into the form of an equation for the $\mathrm{OH}^{-}$ions flow, coupled with the $\mathrm{Na}^{+}$ions transport. By solving the converse problem of this equation, the determinant $\mathrm{OH}^{-}$ions electro-diffusion coefficient is calculated and then, after taking the experimental test results into account, its numerical values, the range of stable solutions and the influence of the process non-stationariness are determined.
\end{abstract}

Keywords: concrete, reinforcement corrosion, electrochemical realkalization, pore solution tests, process modelling.

\section{Introduction}

The influence of the atmosphere on reinforced concrete structures causes the carbonation of concrete (Kamaitis 2008). As a result of this process, a reduction in the concrete cover protective properties occurs, along with an increased corrosion hazard for the reinforcement. The corrosion hazard can be reduced - and at the same time the durability of structures extended - by electrochemical realkalization treatment.

During the electrochemical realkalization of carbonated concrete there occur complex chemical phenomena which basically change the properties of the concrete cover (Mietz 1998; Yeih, Chang 2005; Miranda et al. 2006; Castellote et al. 2006; Bertolini et al. 2008). A scheme of the realkalization process is shown in Fig. 1.

The main source of the changes in the concrete structures is the outer electric field being generated between the reinforcement 1 and the metal mesh 2 on the concrete surface in alkaline electrolyte 3 . On the reinforcement surface 1 there come into being hydroxyl $\mathrm{OH}^{-}$ ions, which, together with the same ions naturally existing in the pore solution, flow towards the anodic mesh 2 . On the anodic mesh 2 there are produced $\mathrm{H}^{+}$ions, which, together with the identical ions from the pore solution, flow into the opposite direction. As a result of the influence of the electric field, also other ions contained in the concrete pore solution are displaced, especially the $\mathrm{Ca}^{2+}$, $\mathrm{K}^{+}, \mathrm{Na}^{+}$cations and the $\mathrm{CO}_{3}{ }^{2-}$ anions. The $\mathrm{Na}^{+}$and $\mathrm{CO}_{3}{ }^{2-}$ ions not only appear in the pore solution but also penetrate into the structure of the concrete cover as they come from the outer electrolyte 3 , which is an $\mathrm{Na}_{2} \mathrm{CO}_{3}$ solution (Mietz 1998). An increase in the number of the $\mathrm{OH}^{-}$and $\mathrm{Na}^{+}$ions causes a dramatic increase in the level of the reduced by carbonation alkaline reaction in the pore solution, and this, in turn, causes a rebuilding of the protective passive layer on the steel surface and a cessation in the reinforcement corrosion.

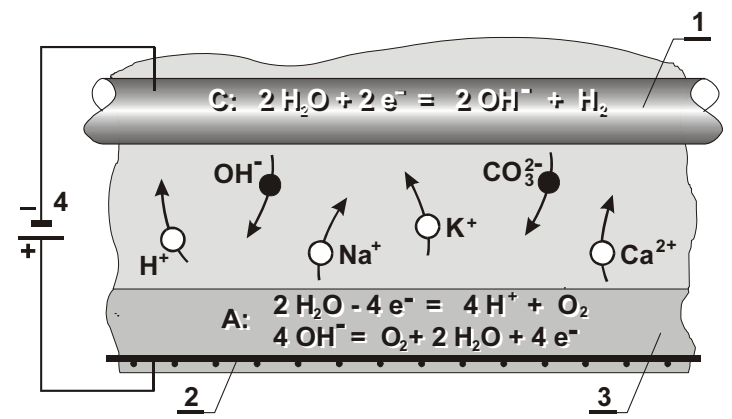

Fig. 1. Scheme of chemical changes in concrete being realkalized (description in the text)

All of the process ion components flow through the system of capillary and gel pores by means of the liquid adsorbed on the walls. The flowing of these components causes a change in their concentration, especially towards the concrete cover thickness.

A model of the electrochemical carbonated concrete realkalization is presented in the paper, a model which has been compiled on the basis of the multi-component medium theory (Bowen 1976; Kubik 1985) using also the data obtained from the tests of the ionic concentration distribution in the pore solution. The analysis of the balance equations of mass, electric charge, momentum, energy, and entropy inequality have made it possible to create a general form of the ion flow equations, whereas the laboratory test results have made it possible to use acceptable simplifications. 
With the converse problem of the diffusion equation solved, we have obtained the integral formulas which define the determinant electro-diffusion coefficient, of fundamental significance in the realkalization process of the $\mathrm{OH}^{-}$ions, and their numerical values resulting from the concentration tests.

The model being suggested is different from the existing methods used for solving similar problems, in which methods of electrochemical equations are used for describing the motions of the ions in electrolyte solutions (Andrade et al. 1995; Castellote et al. 2000; Toumi et al. 2007). However, a multi-component medium theory has analytically described the diffusion processes of chlorides in concrete, taking into account $\mathrm{Cl}^{-}$ions, accompanying $\mathrm{Na}^{+}$ions and chemically bounded chlorides (Zybura 2007 ) and ion migration in concrete cover under the influence of an electric field during electrochemical chloride extraction process (Ali, Zybura 2008).

\section{General equations of the realkalization}

For an analytical description of the process thermomechanical equations of multi-component medium theory have been used (Bowen 1976; Kubik 1985). Taken into consideration is the fact that the concrete cover being exposed to realkalization (Fig. 2a) consists of some aggregate 1 joined together by means of a hardened cement gel 2 (Fig. 2b). In the cement gel 2 there are capillary pores 3 connected to gel pores 4 (Fig. $2 \mathrm{c}$ ). From the cover a representative elementary volume (REV) ' $\mathrm{X}$ ' is abstracted, including pores with a solution 5 adsorbed at their walls, and carbonation products deposited 6 (Fig. 2d). The realkalization proceeds relatively quickly what enables to pass the deposition of $\mathrm{CaCO}_{3}$ in the pores over. Thanks to the pore solution there is a flow of basic process components: $1-\mathrm{OH}^{-}$ions, $2-\mathrm{Na}^{+}$ions, $3-\mathrm{H}^{+}$ ions, $4-\mathrm{CO}_{3}^{2-}$ ions, $5-\mathrm{K}^{+}$ions, $6-\mathrm{Ca}^{2+}$ ions, $7-\mathrm{O}_{2}$ particles and $8-\mathrm{H}_{2}$ particles. The abstracted REV is modelled using a medium including an immobile framework $\alpha=0$ and mobile components - negative ions $\alpha=$ 1,4 , positive ions $\alpha=2,3,5,6$ and electrically neutral particles $\alpha=7,8$ (Fig. 2e). The mass density $\rho^{\alpha}$ of individual components $\alpha$ and the vectors of total velocity $\mathbf{v}^{\alpha}$ are taken into account and then the total velocity is divided into the velocity of centre of gravity $\mathbf{w}$ and the diffusion velocity $\mathbf{u}^{\alpha}$ (Fig. 2f).

The global balance of each component $\alpha$ is determined by the equation

$$
\frac{d}{d t} \int_{V} \rho^{\alpha} d V=\int_{V} R^{\alpha} d V, \quad \alpha=0,1,2, \ldots, 8,
$$

in which $\mathrm{R}^{\alpha}$ is the mass source while $\mathrm{d} / \mathrm{dt}$ means the material time operator.

After having taken into consideration the connections

$$
\begin{aligned}
& \rho=\sum_{\alpha} \rho^{\alpha}, \quad C^{\alpha}=\rho^{\alpha} / \rho, \\
& \mathbf{v}^{\alpha}=\mathbf{w}+\mathbf{u}^{\alpha}, \quad \mathbf{j}^{\alpha}=\rho^{\alpha} \mathbf{u}^{\alpha},
\end{aligned}
$$

we reduce the equation (1) to a partial equation of mass balance

$$
\rho \frac{d C^{\alpha}}{d t}=R^{\alpha}-\operatorname{div} \mathbf{j}^{\alpha},
$$

where $\rho$ is mass density of the whole REV ' $X$ ', $\mathbf{j}^{\alpha}-$ mass flux vector of component $\alpha, \mathrm{C}^{\alpha}-$ its concentration.

Migration of ions is accompanied by the flow of electric charge. The partial balance equations of this charge are obtained by taking into consideration that the mass unit of ions transmits a constant number of electric charges $\mathrm{e}^{\alpha}$.

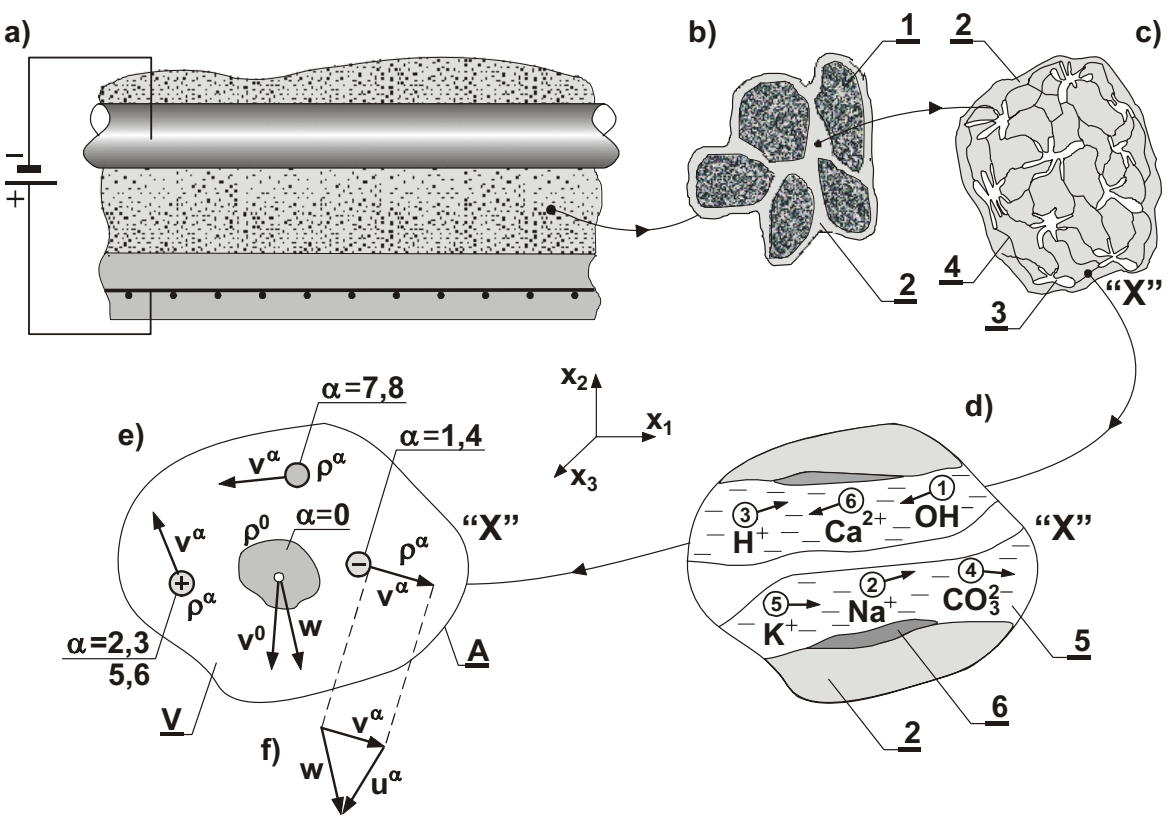

Fig. 2. Multi-component model of carbonated concrete electrochemical realkalization process (description in the text) 
The global balance of electric charge of component $\alpha$ is determined by the equation

$$
\frac{d}{d t} \int_{V} e^{\alpha} \rho^{\alpha} d V=\int_{V} e^{\alpha} R^{\alpha}, \quad \alpha=0,1,2, \ldots, 6,
$$

where $\mathrm{e}^{\alpha} \mathrm{R}^{\alpha}$ is a source of electric charge.

With transformations and substitution of dependences made

$$
\begin{aligned}
& \mathbf{i}^{\alpha}=e^{\alpha} \mathbf{j}^{\alpha} \quad \sum_{\alpha} e^{\alpha} \rho^{\alpha}=e \rho, \\
& \sum_{\alpha} \mathbf{i}^{\alpha}=\mathbf{i}, \quad \sum_{\alpha} e^{\alpha} R^{\alpha}=0,
\end{aligned}
$$

a relation is received

$$
\frac{\partial(\rho e)}{\partial t}+\operatorname{div}(\rho e \mathbf{w})+\operatorname{div} \mathbf{i}=0
$$

where $\mathbf{i}^{\alpha}$ means a partial density vector of diffusion current, e $\rho$ - space charge, $\mathbf{i}$ - total density of diffusion current.

Individual components $\alpha$ existing in the concrete cover are subjected to the action of forces (Fig. 3).

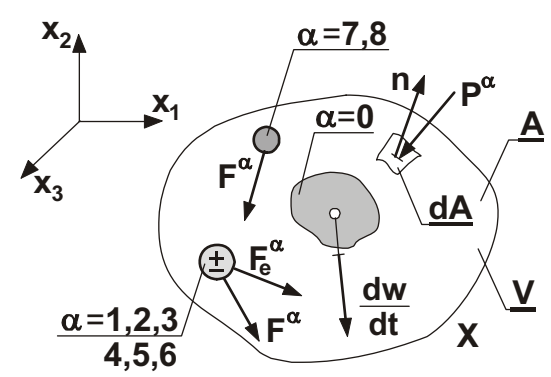

Fig. 3. Scheme of forces acting on process components

The relation between the forces existing in the REV ' $\mathrm{X}$ ' is described by the momentum balance equation

$$
\begin{aligned}
& \sum_{\alpha} \frac{d}{d t} \int_{V} \rho^{\alpha} \mathbf{v}^{\alpha} d v= \\
& \int_{V \alpha}\left(\rho^{\alpha} \mathbf{F}^{\alpha}+\rho^{\alpha} \mathbf{F}_{e}^{\alpha}\right) d V+\int_{A \alpha} \mathbf{P}^{\alpha} d A,
\end{aligned}
$$

where $\mathbf{F}^{\alpha}$ is mass force of component $\alpha, \mathbf{F}_{\mathrm{e}}^{\alpha}-$ force of the electric field action onto the electric charge of an electrically non-neutral component, $\mathbf{P}^{\alpha}-$ partial force of area force.

By determining the acting force of an electric field, via the Lorentz formula, and taking into consideration the relations

$$
\mathbf{P}^{\alpha}=\boldsymbol{\sigma}^{\alpha} \mathbf{n}, \quad \boldsymbol{\sigma}=\sum_{\alpha} \boldsymbol{\sigma}^{\alpha}, \quad \frac{d \mathbf{w}}{d t} \cong 0,
$$

the momentum balance equation is simplified to the form

$$
\rho \mathbf{F}+\rho e \mathbf{E}+\operatorname{div} \boldsymbol{\sigma} \cong 0,
$$

where $\mathbf{F}$ means mass force of the particle ' $\mathrm{X}$ ', $\mathbf{E}$ - vector of electric field intensity, $\boldsymbol{\sigma}^{\alpha}, \boldsymbol{\sigma}-$ tensors of partial and total strength.
The processes occurring in the cover exposed to an action of the electric field cause energetic changes, which are expressed by the energy balance equation

$$
\begin{aligned}
& \sum_{\alpha} \frac{d}{d t} \int_{V} \rho^{\alpha}\left(U^{\alpha}+K^{\alpha}\right) d V= \\
& \sum_{\alpha} \int_{V}\left[\rho^{\alpha} r^{\alpha}+\rho^{\alpha}\left(\mathbf{F}^{\alpha}+\mathbf{F}_{e}^{\alpha}\right) \mathbf{v}^{\alpha}+E^{\alpha}\right] d V+ \\
& \sum_{\alpha} \int_{A}\left(\mathbf{P}^{\alpha} \mathbf{v}^{\alpha}-\mathbf{q}^{\alpha}\right) d A, \quad K^{\alpha} \cong 0,
\end{aligned}
$$

where $\mathrm{U}^{\alpha}, \mathrm{K}^{\alpha}$ mean the internal and kinetic energy of the unit mass of component $\alpha, \rho^{\alpha} r^{\alpha}-$ partial source of heat, $\mathrm{E}^{\alpha}$ - internal transmission of energy, $\mathbf{q}^{\alpha}$ - partial flux of heat.

Into the transformed expression (10) the momentum balance equation (9) and the mass balance equations (3) are introduced, summings are made

$$
\begin{gathered}
\sum_{\alpha}\left(\rho^{\alpha} \frac{d U^{\alpha}}{d t}\right)=\rho \frac{d U}{d t}, \\
\sum_{\alpha} \rho^{\alpha} r^{\alpha}=\rho r, \sum_{\alpha} \mathbf{q}^{\alpha}=\mathbf{q}
\end{gathered}
$$

and the energy balance equation (10) becomes reduced to the form

$$
\begin{aligned}
& \rho \frac{d U}{d t}=\rho r-\operatorname{div} \mathbf{q}+\boldsymbol{\sigma}: \mathbf{d}+ \\
& \sum_{\alpha} M^{\alpha} \rho \frac{d C^{\alpha}}{d t}-\sum_{\alpha} \mathbf{j}^{\alpha} \operatorname{grad} M^{\alpha}-\mathbf{E} \dot{\mathbf{D}}-\mathbf{E} \rho e \mathbf{w} .
\end{aligned}
$$

In the above expression

$$
M^{\alpha}=U^{\alpha}-\frac{\operatorname{tr} \boldsymbol{\sigma}^{\alpha}}{\rho^{\alpha}}
$$

means electrochemical potential of component $\alpha, \operatorname{tr} \boldsymbol{\sigma}^{\alpha}-$ trace of partial strength tensor and $U$ is internal energy of mass unit of REV 'X', $\rho r$ - is source of heat, $\mathbf{q}$ - flux of heat, $\boldsymbol{d}=\dot{\boldsymbol{\varepsilon}}-$ tensor of strain velocity, $\mathbf{D}-$ vector of electric induction.

Because the electro-diffusion process of the components of the cover is under the influence of an electric field, it has a non-reversible character, therefore the inequality of entropy increase must be fulfilled. This increase is established via the relation

$$
\rho \frac{d S}{d t} \geq \frac{\rho r}{T}-\operatorname{div} \mathbf{q}+\frac{\mathbf{q}}{T} \operatorname{grad} T
$$

where $\mathrm{S}$ is the entropy of the unit mass of REV ' $\mathrm{X}$ ', $\mathrm{T}-$ absolute temperature.

Into the inequality (14) the energy balance equation (12) was placed and the constitutive equations were introduced, which equations express internal energy $\mathrm{U}$, entropy $\mathrm{S}$, and electric field intensity $\mathbf{E}$, using a new function - free energy A

$$
\rho A=\rho U-\rho S T+\mathbf{E D} .
$$


Taking into consideration that the free energy A is a function of process parameters: components concentration $\mathrm{C}^{\alpha}$, temperature $\mathrm{T}$, electric field intensity $\mathbf{E}$ and deformation $\boldsymbol{\varepsilon}$

$$
A=A\left(C^{\alpha}, T, \mathbf{E}, \mathbf{\varepsilon}\right)
$$

its derivative to time

$$
\frac{d A}{d t}=\sum_{\alpha} \frac{\partial A}{\partial C^{\alpha}} \frac{d C^{\alpha}}{d t}+\frac{\partial A}{\partial T} \frac{\partial T}{d t}+\frac{\partial A}{\partial \mathbf{E}} \frac{\partial \mathbf{E}}{\partial t}+\frac{\partial A}{\partial \boldsymbol{\varepsilon}} \frac{\partial \boldsymbol{\varepsilon}}{\partial t}
$$

and then the final form of the residual inequality

$$
\begin{aligned}
& -\sum_{\alpha}\left(\frac{\partial A}{\partial C^{\alpha}}-M^{\alpha}\right) \rho \frac{d C^{\alpha}}{d t}-\left(\frac{\partial A}{\partial T}+S\right) \rho \frac{d T}{d t}- \\
& \left(\frac{\partial A}{\partial \mathbf{E}}-\frac{1}{\rho} \mathbf{D}\right) \rho \frac{d \mathbf{E}}{d t}-\left(\rho \frac{\partial A}{\partial \mathbf{\varepsilon}}-\boldsymbol{\sigma}\right): \mathbf{d}-\mathbf{E} \rho e \mathbf{w}- \\
& \sum_{\alpha} \mathbf{j}^{\alpha} \operatorname{grad} M^{\alpha}-\frac{\mathbf{q}}{T} \operatorname{grad} T \geq 0
\end{aligned}
$$

are established. Because the residual inequality (18) must be fulfilled regardless of the process history, it is therefore also justified when multipliers at the derivatives are equal to zero and the other components are greater and equal to zero. On the basis of this property, the limitation conditions are established

$$
\begin{aligned}
& M^{\alpha}=\frac{\partial A}{\partial C^{\alpha}}, \quad S=-\frac{\partial A}{\partial T}, \\
& \mathbf{D}=\rho \frac{\partial A}{\partial \mathbf{E}}, \quad \boldsymbol{\sigma}=\rho \frac{\partial A}{\partial \boldsymbol{\varepsilon}},
\end{aligned}
$$

$$
\mathbf{j}^{\alpha} \operatorname{grad} M^{\alpha} \leq 0, \quad \mathbf{q} \operatorname{grad} T \leq 0 .
$$

Derived from the above conditions are constitutive equations, which determine among other things the electrochemical potential $\mathrm{M}^{\alpha}$ of component $\alpha$, which is equal to the derivative of the free energy $\mathrm{A}$, in relation to the concentration of this component. In a similar way, too, constitutive equations also determine entropy $\mathrm{S}$, intensity of electric field $\mathbf{D}$ and stress $\boldsymbol{\sigma}$. The inequalities (20) make it justifiable to accept the forms of equation as apt descriptions of the mass flux $\mathbf{j}^{\alpha}$ of components $\alpha$ and the heat flux $\mathbf{q}$

$$
\mathbf{j}^{\alpha}=-D^{\alpha} \operatorname{grad} M^{\alpha}, \quad \mathbf{q}=-k \operatorname{grad} T,
$$

where $\mathrm{D}^{\alpha}$ means diffusion coefficient of component $\alpha$ in the medium which models the concrete cover, $\mathrm{k}-$ coefficient of heat conductivity.

\section{Realkalization of specimens and pore solution tests}

Based on the premise of a theoretical model, experimental tests were carried out using specimens measuring $60 \times 100 \times 100 \mathrm{~mm}$ with two centrally located reinforcement rods with a diameter of $6 \mathrm{~mm}$. The thickness of the cover was $25 \mathrm{~mm}$, the concrete had a characteristic compressive strength of $\mathrm{f}_{\mathrm{ck} \text {,cube }}=32,5 \mathrm{MPa}$, which was determined on 15 cubes. The tests were carried out using 18 specimens exposed for 6 months to artificial carbonation in a chamber where carbon dioxide concentration was in the $3 \div 6 \%$ range. The carbonation progress was determined on the evidence of fresh fractures on the additional elements (specimens) moistened by means of the indicator containing phenolphthalein. The carbonation was continued until $\mathrm{pH} \cong 10$ had been obtained. Six carbonated specimens (series RA-14) were realkalized for 14 days, then 6 specimens (series RA-28) were realkalized for 28 days, whereas the 6 remaining specimens (series RA-0) were not realkalized since they were kept as a comparative benchmark.

The realkalization was performed in liquid electrolyte ( $1 M \mathrm{Na}_{2} \mathrm{CO}_{3}$ solution) using a steel anodic mesh and a stabilized direct current source. The two electric circuits were supplied with current simultaneously. On each circuit there were 3 specimens connected in series (Fig. 4).

Six elements were being realkalized at the same time. The progress of the realkalization was controlled by measuring the circuit current intensity and the voltage between the specimen reinforcement and the anodic mesh. At first the current intensity was $2 \div 4 \mathrm{~mA}$, then it grew very fast to achieve the targeted value of $10 \mathrm{~mA}$ after $2-5$ days. Similarly the voltage varied for the first few days within the $10 \div 34 \mathrm{~V}$ range and after that period there was a stabilization at the level of $10 \mathrm{~V}-5 \mathrm{~V}$.

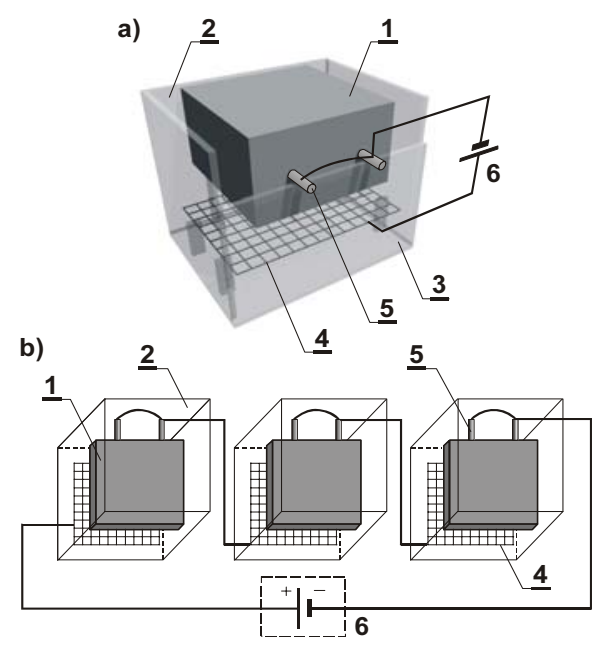

Fig. 4. Laboratory tests of realkalization process: a) view of testing station, b) circuit diagram; 1 - specimen, 2 container, 3 - electrolyte, 4 - anodic mesh, 5 - reinforcement, 6 - direct current power

After the realkalization had been carried out, ground concrete specimens were taken from the cover reinforcement by at least 5-mm-thick layers. The technique of the test material removal is shown on Fig. 5.

The mass obtained from a single layer was quite small - about 45 grams of the material was needed. In order to obtain enough material for the chemical analyses, the ground concrete from corresponding layers of the 6 specimens of a given series was put together to have sufficient material to represent averaged properties of 5 consecutive layers separated from the cover.

A model pore solution was made from the ground concrete. The modelling of the solution was carried out using the vacuum extraction method, which consists in 
concentrating the water extract proportionally to the concrete humidity (Wieczorek 2002). The water extract was made from the ground concrete and the distilled water by a weight ratio of $1: 1$. The vacuum concentration of the water extract was proceeded in boiling state under pressure $\sim 0,004 \mathrm{MPa}$ and temperature $25-30{ }^{\circ} \mathrm{C}$. Assuming that during the realkalization process the specimen humidity was $10 \%$, therefore the water extract from the ground concrete had been concentrated 10 times. a)
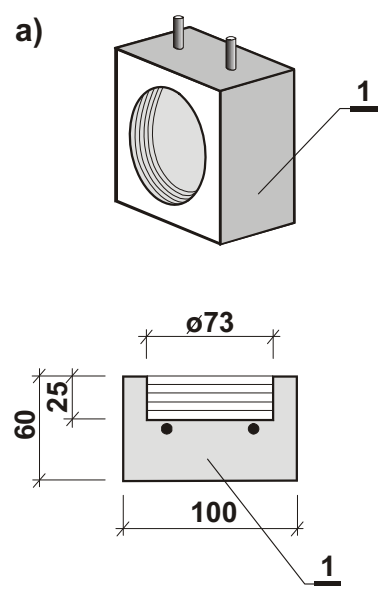

b)

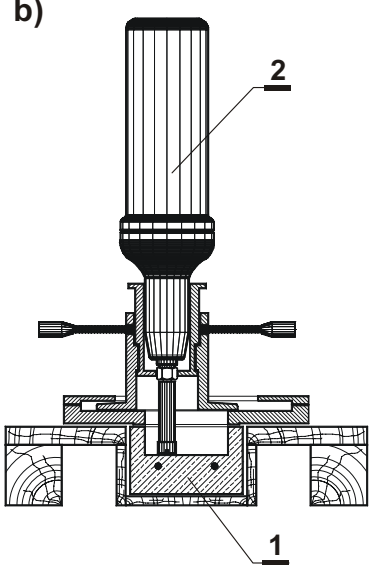

Fig. 5. Concrete grinding by layers: a) view and crosssection of specimen with concrete taken by layers, b) view of stand for concrete grinding; 1 - specimen, 2 - concrete layer grinding device

On the basis of the chemical tests, concentrations of the main ions $\mathrm{OH}^{-}, \mathrm{Na}^{+}, \mathrm{K}^{+}, \mathrm{Ca}^{2+}$ and $\mathrm{CO}_{3}{ }^{2-}$ were determined; their values are shown in Figs 6 and 7.
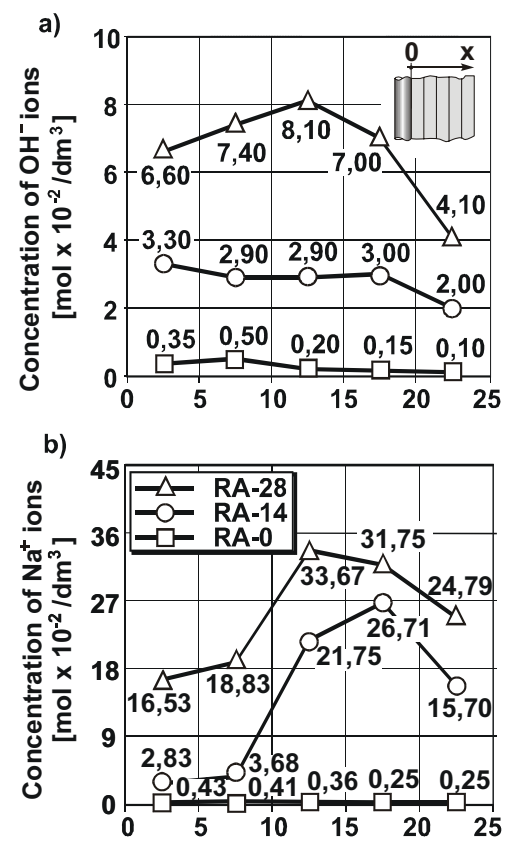

Ordinates of concrete cover layers $x[\mathrm{~mm}]$

Fig. 6. Distributions of molar concentrations: a) $\mathrm{OH}^{-}$ions, b) $\mathrm{Na}^{+}$ions

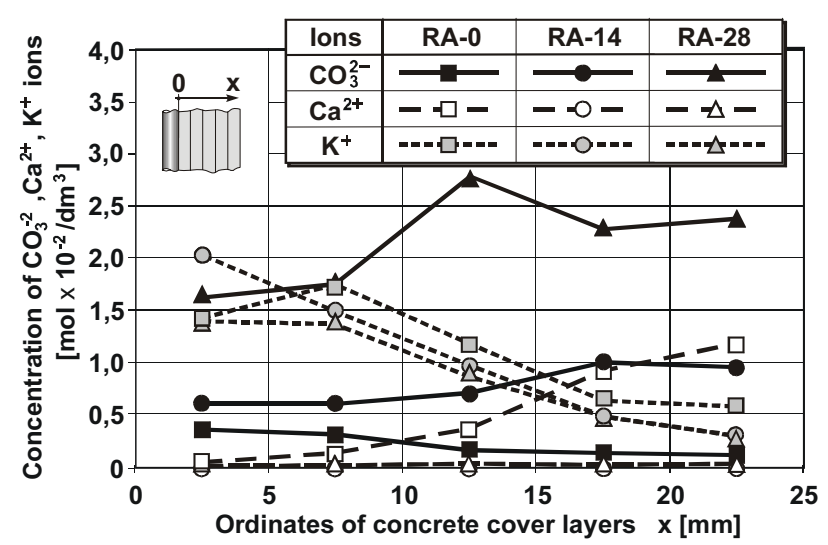

Fig. 7. Distributions of molar concentrations $\mathrm{CO}_{3}{ }^{2-}, \mathrm{Ca}^{2+}$ and $\mathrm{K}^{+}$ions

Altogether 15 model solutions were analysed. 5 solutions were obtained from the concrete of the carbonated specimens (RA-0), 5 solutions - from the concrete of the 14-day-realkalized specimens (RA-14) and 5 solutions - from the concrete of the 28-day-realkalized specimens (RA-28). Each solution in a given specimen group corresponded to one of the 5 layers separated on the thickness of the cover. The concentration of $\mathrm{OH}^{-}$and $\mathrm{CO}_{3}{ }^{2-}$ ions was determined by means of the titration, that of $\mathrm{Na}^{+}$and $\mathrm{K}^{+}$, using the flame photometry and that of $\mathrm{Ca}^{2+}$ ions, using the complexometric method. The results of the chemical tests were correlated with the location of a layer taken from the cover.

The obtained results of the concentrations did point clearly at the time related differences in the distributions of $\mathrm{OH}^{-}$and $\mathrm{Na}^{+}$ion densities. The changes of the $\mathrm{K}^{+}$, $\mathrm{Ca}^{2+}$ and $\mathrm{CO}_{3}{ }^{2-}$ ion densities were not big ones and moreover the content of these ions in a pore solution was considerably smaller than that of $\mathrm{OH}^{-}$and $\mathrm{Na}^{+}$ions.

\section{Ion flow equations during realkalization}

The experimental tests have shown that the electrochemical realkalization caused an important change of $\mathrm{OH}^{-}$and $\mathrm{H}^{+}$ion concentrations and produced some minor rearrangements of other ions. These results make it possible to simplify the general theoretical model and to represent the process using a medium with 2 mobile components and with one immobile component. The immobile component includes, apart from the framework with a pore solution, also other less significant ions and particles.

On the basis of the dependences $(1) \div(4)$, the partial equations were established:

$$
\begin{aligned}
& \frac{\partial \rho^{0}}{\partial t}=0,(\alpha=0-\text { framework }), \\
& \frac{\partial \rho^{1}}{\partial t}+\operatorname{div}\left(\rho^{1} \mathbf{v}^{1}\right)=R^{1},\left(\alpha=1-\text { anion } \mathrm{OH}^{-}\right), \\
& \frac{\partial \rho^{2}}{\partial t}+\operatorname{div}\left(\rho^{2} \mathbf{v}^{2}\right)=R^{2},\left(\alpha=2-\text { cation } \mathrm{Na}^{+}\right),
\end{aligned}
$$

and the partial equations of the electric charge balance 


$$
\begin{aligned}
& \frac{\partial\left(e^{1} \rho^{1}\right)}{\partial t}+\operatorname{div}\left(e^{1} \rho^{1} \mathbf{v}^{1}\right)=e^{1} R^{1},(\alpha=1), \\
& \frac{\partial\left(e^{2} \rho^{2}\right)}{\partial t}+\operatorname{div}\left(e^{2} \rho^{2} \mathbf{v}^{2}\right)=e^{2} R^{2},(\alpha=2) .
\end{aligned}
$$

In the above equations: $R^{1}, R^{2}$ mean sources of component mass, $\mathrm{e}^{1}, \mathrm{e}^{2}-$ electric charges of the unit mass of these components, $\mathrm{t}$ - time.

The non-dimensional components concentration is used

$$
C^{1}=\rho^{1} / \rho, C^{2}=\rho^{2} / \rho, \rho=\rho^{1}+\rho^{2},
$$

and then the mass balance equations $(22) \div(24)$ and the electric charge balance equations (25), (26) are summed up by sides to receive a system of 2 equations

$$
\begin{aligned}
& \rho\left(\frac{\partial C^{1}}{\partial t}+\frac{\partial C^{2}}{\partial t}\right)+\operatorname{div}\left(\mathbf{j}^{1}+\mathbf{j}^{2}\right)=0 \\
& \boldsymbol{j}^{1}=\rho \boldsymbol{u}^{1}, \quad \dot{j}^{2}=\rho \boldsymbol{u}^{2} \\
& \frac{\partial e \rho}{\partial t}+\operatorname{div}\left(e^{1} \mathbf{j}^{1}+e^{2} \mathbf{j}^{2}\right)=0, \quad e^{1} \rho^{1}+e^{2} \rho^{2}=e \rho
\end{aligned}
$$

taking into account the law of conservation of mass and electric charge

$$
\sum R=R^{1}+R^{2}=0, \quad \sum e R=e^{1} R^{1}+e^{2} R^{2}=0 .
$$

Into the equations (28) and (29) the physical relations characterizing mass fluxes are placed. These relations have been assumed in accordance with the limitations (20) resulting from the residual inequality analysed - see formula (21)

$$
\mathbf{j}^{1}=-D^{1} \operatorname{grad} M^{1}, \quad \mathbf{j}^{2}=-D^{2} \operatorname{grad} M^{2},
$$

where $D^{1}$ and $D^{2}$ are diffusion coefficients of both process components, while $M^{1}$ and $M^{2}-$ electrochemical potentials.

In accordance with the expression (19), it was taken into account, that the electrochemical potential of the component $\alpha$ is a derivative of the free energy A of the medium in relation to the concentration $C^{\alpha}$ of this component, while according to formula (15) the free energy is a function of the process parameters; among other things components concentration $C^{\alpha}$ and electric field potential $\varphi(\mathbf{E}=-\operatorname{grad} \varphi)$. On this basis the electrochemical potential of components $\alpha=1,2$ has been approximated using the linear function of the concentration $C^{1}$ and $C^{2}$ and the work done by the electric charges of the components mass unit in an electric field with potential $\varphi$

$$
\begin{aligned}
& M^{1} \cong \gamma^{11} C^{1}+\gamma^{12} C^{2}+\delta^{11} e^{1} \varphi+\delta^{12} e^{2} \varphi, \\
& M^{2} \cong \gamma^{21} C^{1}+\gamma^{22} C^{2}+\delta^{21} e^{1} \varphi+\delta^{22} e^{2} \varphi .
\end{aligned}
$$

In another simplification there were adopted values of coefficients $\gamma^{11}=\gamma^{22}=1, \gamma^{12}=\gamma^{21}=0, \delta^{11}=\delta^{22}=1$, $\delta^{12}=\delta^{21}=0$. The $\mathrm{Na}^{+}$ions concentration in a pore solution is a function of the $\mathrm{OH}^{-}$ions concentration (Wiec- zorek 2002). Concentration $C^{2}$ of component $\alpha=2$ can be expressed by means of the concentration $C^{1}, C^{2}=$ $C^{2}\left(C^{1}\right)$

$$
\begin{gathered}
\frac{\partial C^{2}}{\partial t}=\frac{\partial C^{2}}{\partial C^{1}} \frac{\partial C^{1}}{\partial t}=k \frac{\partial C^{1}}{\partial t}, \\
\frac{\partial C^{2}}{\partial x_{i}}=\frac{\partial C^{2}}{\partial C^{1}} \frac{\partial C^{1}}{\partial x_{i}}=k \operatorname{grad} C^{1}, \quad k=\frac{\partial C^{2}}{\partial C^{1}} .
\end{gathered}
$$

By transforming the formulas (31), (32) and (33) into the dependences (28) and (29) you can obtain a system of equations

$$
\begin{gathered}
\rho \frac{\partial C^{1}}{\partial t}(1+k)=\operatorname{div}\left[\beta_{1} \operatorname{grad} C^{1}+\beta_{2} \operatorname{grad} \varphi\right], \\
\frac{\partial e \rho}{\partial t}=\operatorname{div}\left[\beta_{3} \operatorname{grad} C^{1}+\beta_{4} \operatorname{grad} \varphi\right]
\end{gathered}
$$

in which

$$
\begin{array}{cc}
\beta_{1}=D^{1}+D^{2} k, & \beta_{2}=D^{1} e^{1}+D^{2} e^{2}, \\
\beta_{3}=D^{1} e^{1}+D^{2} e^{2} k, & \beta_{4}=D^{1} e^{1} e^{1}+D^{2} e^{2} e^{2}
\end{array}
$$

are auxiliary parameters expressing connections between the diffusion coefficients of individual components. Taken into consideration is the fact that the changes of the space charge in time are very slow $(\partial e \rho / \partial t \cong 0)$ and the sum of the densities of the diffusion currents corresponds to the density of the external current $\mathbf{I}\left(\mathrm{e}^{1} \mathbf{j}^{1}+\right.$ $\left.\mathrm{e}^{2} \mathbf{j}^{2}=\mathbf{I}\right)$. These simplifications make it possible to derive the formula

$$
\operatorname{grad} \varphi=\frac{1}{\beta_{4}} \mathbf{I}-\frac{\beta_{3}}{\beta_{4}} \operatorname{grad} C^{1}, \quad \mathbf{I}=\text { const }
$$

from the dependence (35) and then to transform the equation (34) into a form, which approximately corresponds to the classical diffusion equation

$$
\rho(1+k) \frac{\partial C^{1}}{\partial t}=\operatorname{div}\left(D_{e d} \operatorname{grad} C^{1}\right) .
$$

The equation (38) describes the electro-diffusion flow of $\mathrm{OH}^{-}$ions (component $\alpha=1$ ) which flow is coupled with the $\mathrm{Na}^{+}$ions transport (component $\alpha=2$ ). Under the divergence operator there appears a determinant electro-diffusion coefficient which is expressed by the formula

$$
\begin{aligned}
D_{e d}= & \beta_{1}-\frac{\beta_{2} \beta_{3}}{\beta_{4}}= \\
& \frac{D^{1} D^{2}\left[k e^{1} e^{1}-(1+k) e^{1} e^{2}+e^{2} e^{2}\right]}{D^{1} e^{1} e^{1}+D^{2} e^{2} e^{2}} .
\end{aligned}
$$

\section{Determination of diffusion coefficient - the converse problem}

The formula (39) specifies the theoretical connection between the diffusion coefficients of both components $(\alpha=1,2)$ in the flows considered separately. It is quite difficult to put this formula into practice. However, the determinant diffusion coefficient can be established by 
solving the converse problem of the equation (38), which expresses the measurable process parameters relatively easily.

The cover of the reinforcement can be parameterized using the Cartesian co-ordinate system. The exterior surface of the element corresponds to the plane $\mathrm{x}=\mathrm{c}$, while the contact between the concrete and the reinforcement insert is described by the parallel plane $\mathrm{x}=0$ (Fig. 8).

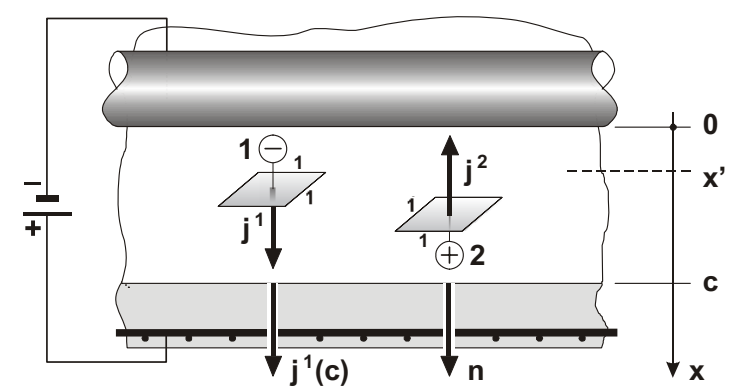

Fig. 8. Flow diagram for formulating converse problem of diffusion equation in concrete electrochemical realkalization process (description in the text)

Two definitions are now introduced: diffusion resistance $Q_{x}$ of the x-thick-concrete layer and diffusion resistance $Q$ of the whole cover

$$
Q_{x}=\int_{0}^{x} \frac{1}{D_{e d}\left(x^{\prime}\right)} d x^{\prime}, \quad Q=\int_{0}^{c} \frac{1}{D_{e d}\left(x^{\prime}\right)} d x^{\prime} .
$$

The equation (38) is multiplied bilaterally by the $Q_{x} / Q$ quotient and then integrated with the thickness of the cover in the $[0, \mathrm{c}]$ range and integrated with time in the $[\mathrm{t}, \mathrm{t}+\Delta \mathrm{t}]$ range

$$
\begin{gathered}
\int_{t}^{t+\Delta t c} \int_{0}^{t c} \frac{Q_{x}}{Q}\left[\rho(1+k) \frac{\partial C^{1}}{\partial t}\right] d x^{\prime} d \tau= \\
\int_{t}^{t+\Delta t c} \int_{0}^{t c} \frac{Q_{x}}{Q}\left[\frac{\partial}{\partial x}\left(D_{e d} \frac{\partial C^{1}}{\partial t}\right)\right] d x^{\prime} d \tau .
\end{gathered}
$$

Once the integration is made and the medium values in the time interval of $\Delta \mathrm{t}$ between the measurements are introduced, the determinant electro-diffusion coefficient can be established

$$
\begin{gathered}
D_{e d}=\frac{1}{Q}=\frac{\overline{\mathbf{j}^{1}}(\mathrm{c}) \mathbf{n} c \Delta t}{\overline{\left.\bar{C}^{1}(0)-\overline{C^{1}}(\mathrm{c})\right] \Delta t-B},} \\
B=\int_{0}^{c} Q_{x} \rho(1+k)\left[C^{1}(x, t+\Delta t)-C^{1}(x, t)\right] d x .
\end{gathered}
$$

On the basis of the chemical tests, the basic parameters appearing in the above formula can be determined: the time averaged boundary concentrations of $\mathrm{OH}^{-}$ions $\overline{\mathrm{C}^{1}}(0)$ and $\overline{\mathrm{C}^{1}}(\mathrm{c})$ as well as the averaged mass flux $\mathbf{j}^{1}(\mathrm{c})$ of the same ions on the cover edge (Fig. 9).

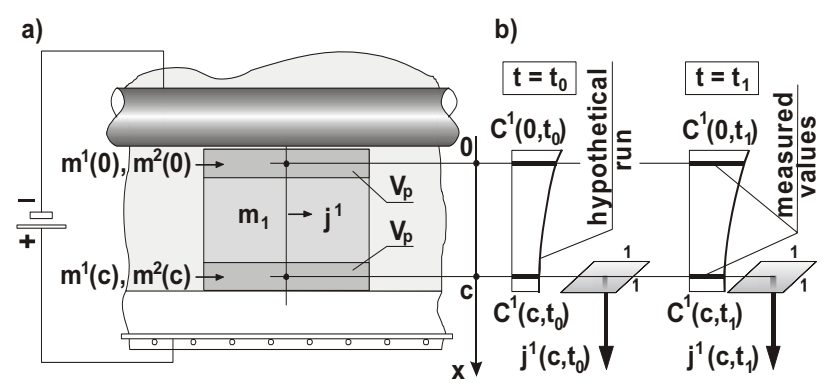

Fig. 9. Method for using test results in theoretical model of realkalization process: a) sampling of ground concrete, b) boundary concentrations and mass fluxes of $\mathrm{OH}^{-}$ions

The formula (42) expresses also: c - cover thickness, $\tilde{\Delta \mathrm{t}}-$ realkalization time and the integral relation describing the non-stationariness influence.

\section{Analysis of the experimental test results}

With the results of the experimental tests and the derived theoretical formulas taken into account, a numerical analysis of the individual realkalization process parameters and the value of the determinant diffusion coefficient of $\mathrm{OH}^{-}$ions has been carried out.

The mass density $\rho^{\alpha}$ of the components $(\alpha=1,2)$ of the medium modelling the concrete cover was determined by the formula

$$
\rho^{\alpha}=\frac{M^{\alpha} w \gamma_{b}}{\gamma_{c}} c^{\alpha},
$$

where $\mathrm{M}^{\alpha}$ is molecular or atomic weight, $\mathrm{w}-$ concrete humidity, $\gamma_{\mathrm{b}}$ and $\gamma_{\mathrm{c}} \sim$ weights of concrete and water by volume, $\mathrm{c}^{\alpha}-$ molar concentration of ions in pore solution.

The mass density $\rho^{1}(\mathrm{x}, \mathrm{t})$ of $\mathrm{OH}^{-}$ions and the mass density $\rho^{2}(x, t)$ of $\mathrm{Na}^{+}$ions were calculated according to the formula (43) and the chemical test results are presented in Fig. 6. Then the values of the hydroxyl ion concentrations were determined for the medium modelling the cover

$$
C^{1}(x, t)=\frac{\rho^{1}(x, t)}{\rho^{1}(x, t)+\rho^{2}(x, t)},
$$

in the centre of the layer with a co-ordinate $x$ and the time $\mathrm{t}=\mathrm{t}_{0}$ - before the realkalization as well as at the time $\mathrm{t}=\mathrm{t}_{1}$ and $\mathrm{t}=\mathrm{t}_{2}$ after the realkalization. The total of the calculation results is in Table 1 .

In order to make the analysis easier, the numerical values of the mass density $\rho^{1}(\mathrm{x}, \mathrm{t})$ of $\mathrm{OH}^{-}$, as shown in Table 1, are graphically presented in Fig. 10. Besides, the main points situated in the centres of the layers under examination, the extreme points $(x=22,5 \mathrm{~mm})$ obtained as a result of the linear approximation are also indicated.

The division of the 25 -mm-thick concrete cover into 5 identical 5-mm-thick layers makes it possible to obtain numerical results of the $D_{\text {ed }}$ coefficient using the data from 4 model layers with calculation boundary coordinates equal to $\mathrm{x}=[0, \mathrm{c}]$ where $\mathrm{c}=20 \mathrm{~mm}$ in case of a layer with its maximum thickness, and $\mathrm{c}=15,10$ and $5 \mathrm{~mm}$ for assumed intermediate layers (Fig. 10). 
Table 1. Calculation results of mass density $\rho^{1}, \rho^{2}$ of $\mathrm{OH}^{-}$and $\mathrm{Na}^{+}$ions and of concentration $\mathrm{C}^{1}$

\begin{tabular}{|c|c|c|c|c|c|c|}
\hline \multirow{2}{*}{$\begin{array}{c}\text { Mass density } \\
\text { and concentration }\end{array}$} & \multirow{2}{*}{$\begin{array}{l}\text { Time } \\
\text { [day] }\end{array}$} & \multicolumn{5}{|c|}{ Calculating ordinates of layers $x[\mathrm{~mm}]$} \\
\hline & & 0 & 5 & 10 & 15 & 20 \\
\hline$\left[\mathrm{g} / \mathrm{m}^{3}\right]$ & \multirow{4}{*}{$\mathrm{t}_{0}=0$} & 12.73 & 18.19 & 7.28 & 5.46 & 3.64 \\
\hline$\left[\mathrm{g} / \mathrm{m}^{3}\right]$ & & $21 . \overline{40}$ & 20.33 & 17.76 & 12.41 & 12.20 \\
\hline$\left[\mathrm{g} / \mathrm{m}^{3}\right]$ & & 34.13 & 38.52 & 25.04 & 17.87 & 15.84 \\
\hline $\mathrm{C}^{1}\left(\mathrm{t}_{0}\right)$ & & 0.373 & 0.472 & 0.291 & 0.305 & 0.230 \\
\hline$\rho^{1}\left(\mathrm{t}_{1}\right) \quad\left[\mathrm{g} / \mathrm{m}^{3}\right]$ & \multirow{4}{*}{$t_{1}=14$} & 120.05 & 105.50 & 105.50 & 109.14 & 72.76 \\
\hline$\left[\mathrm{g} / \mathrm{m}^{3}\right]$ & & 139.10 & 180.83 & 1070.00 & 1313.96 & 772.54 \\
\hline$\rho\left(\mathrm{t}_{1}\right) \quad\left[\mathrm{g} / \mathrm{m}^{3}\right]$ & & 259.15 & 286.33 & 1175.50 & 1423.10 & 845.30 \\
\hline $\mathrm{C}^{1}\left(\mathrm{t}_{1}\right)$ & & 0.463 & 0.368 & 0.090 & 0.077 & 0.086 \\
\hline$\rho^{1}\left(\mathrm{t}_{2}\right) \quad\left[\mathrm{g} / \mathrm{m}^{3}\right]$ & \multirow{4}{*}{$t_{2}=28$} & 240.11 & 269.21 & 294.68 & 254.66 & 149.16 \\
\hline$\left[\mathrm{g} / \mathrm{m}^{3}\right]$ & & 813.20 & 926.62 & 1656.36 & 1562.20 & 1219.80 \\
\hline$\rho\left(\mathrm{t}_{2}\right) \quad\left[\mathrm{g} / \mathrm{m}^{3}\right]$ & & 1053.31 & 1195.83 & 1951.04 & 1816.86 & 1368.96 \\
\hline $\mathrm{C}^{1}\left(\mathrm{t}_{2}\right)$ & & 0.228 & 0.225 & 0.151 & 0.140 & 0.109 \\
\hline
\end{tabular}

Table 2. Calculation results for mass, flux mass and boundary concentrations of $\mathrm{OH}^{-}$ions

\begin{tabular}{|c|c|c|c|c|c|c|c|}
\hline$\Delta \mathrm{t}$ & $\mathrm{c}$ & $m^{\prime}\left(t_{0}=0\right)$ & $m^{1}(t)$ & $\Delta \mathrm{m}^{\prime}$ & $\overline{\mathbf{j}^{1}}(\mathbf{c}) \times 10^{6}$ & $\overline{C^{1}}(x=0)$ & $\overline{C^{1}}(x=c)$ \\
\hline [day] & {$[\mathrm{mm}]$} & {$[\mathrm{mg}]$} & {$[\mathrm{mg}]$} & {$[\mathrm{mg}]$} & {$\left[\mathrm{g} / \mathrm{m}^{2} \cdot \mathrm{s}\right]$} & & \\
\hline \multirow{4}{*}{14} & 20 & 8 & 159 & 151 & 0.125 & 0.418 & 0.158 \\
\hline & 15 & 31 & 614 & 583 & 0.482 & 0.418 & 0.191 \\
\hline & 10 & 63 & 1151 & 1088 & 0.899 & 0.418 & 0.190 \\
\hline & 5 & 126 & 1678 & 1552 & 1.283 & 0.418 & 0.420 \\
\hline \multirow{4}{*}{28} & 20 & 8 & 307 & 299 & 0.124 & 0,300 & 0.169 \\
\hline & 15 & 31 & 1317 & 1286 & 0.532 & 0.300 & 0.223 \\
\hline & 10 & 63 & 2690 & 2627 & 1.086 & 0.300 & 0.221 \\
\hline & 5 & 126 & 4100 & 3973 & 1.642 & 0.300 & 0.349 \\
\hline
\end{tabular}

Table 3. Results of calculations for determinant diffusion coefficient $D_{\text {ed }}$

\begin{tabular}{|c|c|c|c|c|c|c|c|c|}
\hline \multirow{3}{*}{$\begin{array}{c}\Delta \mathrm{t} \\
{[\text { day] }}\end{array}$} & \multirow{3}{*}{$\begin{array}{c}\mathrm{c} \\
{[\mathrm{mm}]} \\
\end{array}$} & \multirow{3}{*}{$\overline{\Delta C^{1}}$} & \multirow{3}{*}{$\begin{array}{l}\mathrm{D}_{\mathrm{ed}}^{\mathrm{st}} \times 10^{9} \\
{\left[\mathrm{~g} \cdot \mathrm{s} / \mathrm{m}^{3}\right]}\end{array}$} & \multicolumn{5}{|c|}{$\mathrm{D}_{\mathrm{ed}}^{\mathrm{nat}} \times 10^{9}\left[\mathrm{~g} \cdot \mathrm{s} / \mathrm{m}^{3}\right]$} \\
\hline & & & & \multicolumn{5}{|c|}{ Influence of process non-stationarimess } \\
\hline & & & & $10 \%$ & $20 \%$ & $30 \%$ & $40 \%$ & $50 \%$ \\
\hline \multirow{4}{*}{14} & 20 & 0.260 & 10 & 11 & 12 & 14 & 16 & 19 \\
\hline & 15 & 0.227 & 32 & 35 & 40 & 45 & 53 & 64 \\
\hline & 10 & 0.228 & 39 & 44 & 49 & 56 & 66 & 79 \\
\hline & 5 & -0.002 & indefinite & \multicolumn{5}{|c|}{ indefinite value } \\
\hline \multirow{4}{*}{28} & 20 & 0.131 & 19 & 21 & 24 & 27 & 31 & 38 \\
\hline & 15 & 0.078 & 103 & 114 & 128 & 147 & 171 & 205 \\
\hline & 10 & 0.080 & 136 & 151 & 170 & 195 & 227 & 273 \\
\hline & 5 & -0.048 & indefinite & \multicolumn{5}{|c|}{ indef mite value } \\
\hline
\end{tabular}

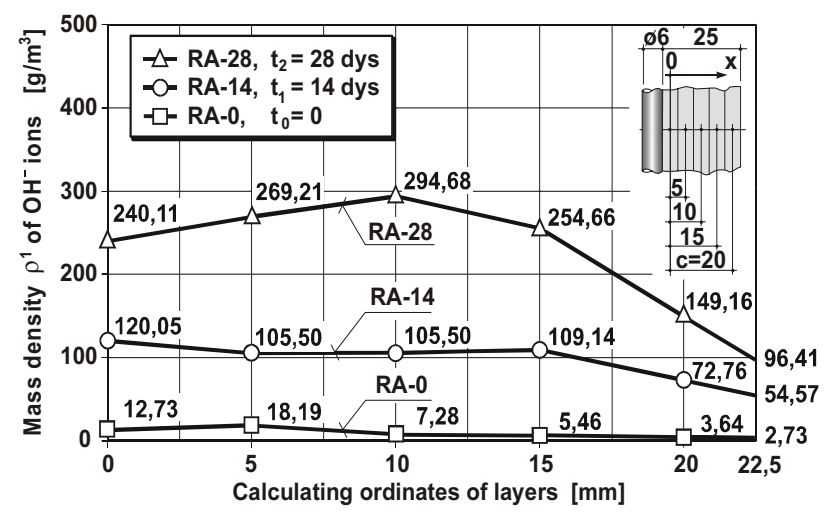

Fig. 10. Distribution of $\mathrm{OH}^{-}$ion mass density in direction of concrete cover thickness

Based on the mass density of hydroxyl ions $\rho^{1}(t)$ after the carbonation $\left(t_{0}=0\right)$ and after the realkalization lasting for $\mathrm{t}_{1}=14$ days, $\mathrm{t}_{2}=28$ days, and based on the concrete volume limited by the unit area $A=1 \mathrm{~m}^{2}$ and the layer thickness $\mathrm{c}$, the hydroxyl ion mass increases were calculated

$$
\Delta m^{1}=m^{1}(t)-m^{1}\left(t_{0}\right), \text { where } m^{1}=c A \rho^{1}(t),
$$

then their mass flux on the cover edge was averaged in time

$$
\overline{\mathbf{j}}^{1}(c)=\frac{\Delta m^{1}}{A \cdot \Delta t} .
$$

The concentration difference has been established by determining the averaged boundary concentrations $\overline{\mathrm{C}^{1}}(\mathrm{x}=0)$ and $\overline{\mathrm{C}^{1}}(\mathrm{x}=\mathrm{c})$ in the relevant time intervals of $\Delta \mathrm{t}=\mathrm{t}_{1}-\mathrm{t}_{0}$ and $\Delta \mathrm{t}=\mathrm{t}_{2}-\mathrm{t}_{0}$

$$
\Delta \bar{C}^{1}=\bar{C}^{1}(x=0)-\bar{C}^{1}(x=c) .
$$

Not taking into account the integral component which expresses the non-stationary influences and using the formula (42) the value of the determinant electrodiffusion coefficient was calculated depending both on the thickness $\mathrm{c}$ of the concrete layer modelling the cover and the concentration difference on the edge of this layer. The calculation results are in Tables 2, 3 . 
A comparison of the averaged values of the hydroxyl ion mass flux, the values of which have been determined in two time intervals (Table 2), proves that the electrochemical realkalization process has an unsteady character through the whole period.

The non-stationariness influence was evaluated, with the integral component values of the formula (42), assumed as part $\gamma$ of the component expressing the stationary influences

$$
\begin{aligned}
& \int_{0}^{c} Q_{x} \rho(1+k)\left[C^{1}(x, t+\Delta t)-C^{1}(x, t)\right] d x= \\
& \gamma\left[\overline{C^{1}}(0)-\overline{C^{1}}(c)\right] \Delta t .
\end{aligned}
$$

Numerical simulation was carried out assuming the fraction value $\gamma=0,1 \div 0,5$. The calculation results are in Table 3.

The diagram illustrating the distribution of the calculated values of the determinant electro-diffusion coefficient $D_{\text {ed }}$ in the process of concrete realkalization are in Fig. 11. The flow of the diagram suggests that as far as the difference of the boundary concentrations $\Delta \overline{\mathrm{C}^{1}}>0,13$ is concerned, the solution is stable, the stability of the solution is uncertain in the range of $0,05<\Delta \overrightarrow{C^{1}} \leq 0,13$, however, non-stable results can be expected with boundary concentration differences equalling $\Delta \overline{\mathrm{C}^{1}}<0,05$.

The simulation of the non-stationary influence of the course of the process indicates the range of mistakes which can be made, when this phenomenon is not taken into account. The assumption that the non-stationariness influence is $10 \%$ of the product of the boundary concentration differences times, the realkalization time caused little increase of the electro-diffusion coefficient - in the order of $10 \%$. The non-stationariness influence identically determined as being $30 \%$ caused the electrodiffusion coefficient to increase by over $40 \%$; however, the $50 \%$ non-stationariness participation increased by twice the value of the electro-diffusion coefficient.

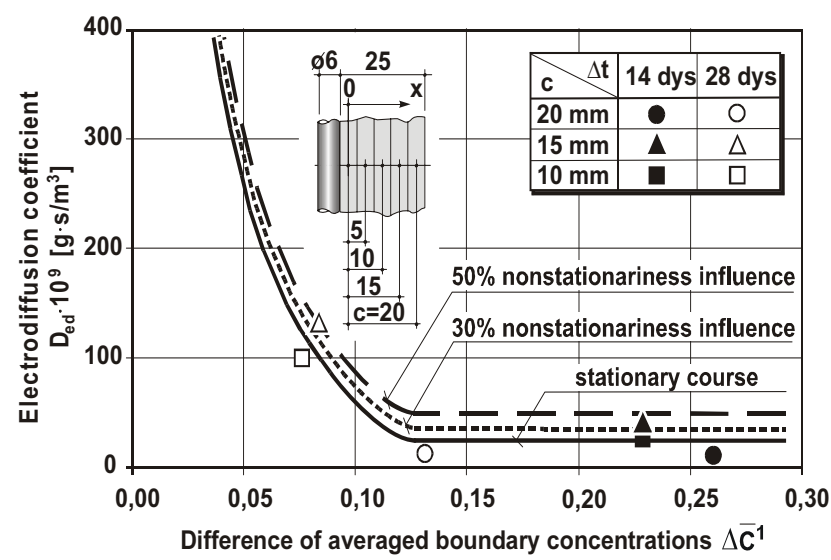

Fig. 11. Dependence of electro-diffusion coefficient on difference of $\mathrm{OH}^{-}$ion boundary concentrations

The physical units of the electro-diffusion coefficient $\left[\mathrm{g} \cdot \mathrm{s} / \mathrm{m}^{3}\right]$ do result from the form of the hydroxyl ion flow equation (38). The concentration $\mathrm{C}^{1}$ under the gradi- ent operator in equation (38) expresses the electrochemical potential of hydroxyl ions, the potential of which was approximated in the model by a linear function (32).

\section{Summary}

A process of carbonated concrete electrochemical realkalization has been described using the multi-component medium theory equations. The equations, expressing mutual relationships between the flows of the basic ions in the pore solution, the electric field and the chemical changes, have been obtained on the basis of an analysis of the partial balance equations of mass, electric charge, momentum, energy, and entropy inequality. With the experimental tests performed it has been stated that the electrochemical realkalization had caused significant changes to the $\mathrm{OH}^{-}$and $\mathrm{Na}^{+}$ions concentration and some small displacements of other ions. These results have made it possible to simplify the problem and to describe the process by means of a model consisting of 2 mobile components corresponding to $\mathrm{OH}^{-}$and $\mathrm{Na}^{+}$ions, and of one immobile component, containing the framework with a pore solution and other less important ions. Following the relations which describe the simplified medium, there has been introduced an equation which determines the electro-diffusion flow of $\mathrm{OH}^{-}$ions coupled with the $\mathrm{Na}^{+}$ ions transport. The solution of the converse problem of this equation in a theoretically justified way has led us to determine the determinant electro-diffusion coefficient of the basic component of the process, i.e., $\mathrm{OH}^{-}$anion. With the $\mathrm{OH}^{-}$ion concentrations measured on the border and their mass fluxes taken into account, the values of the determinant electro-diffusion coefficient have been calculated. The range of stable solutions and the influences of the factors bringing about a non-stationary course of the process have been determined.

\section{References}

Ali, A. R.; Zybura, A. 2008. Application of thermomechanics equations in describing chloride extraction from concrete, Transport in Porous Media 72: 139-156.

Andrade, C.; Diez, J. M.; Ataman, A.; Alonso, C. 1995. Mathematical modelling of electrochemical chloride extraction from concrete, Cement and Concrete Research 25(6): 727-740.

Bertolini, L.; Carsana, M.; Redaelli, E. 2008. Conservation of historical reinforced concrete structures damaged by carbonation induced corrosion by means of electrochemical realkalisation, Journal of Cultural Heritage 9: 376-385.

Bowen, R. M. 1976. Theory of Mixtures in Continuum Physics. Ed. A. C. Eringen, Academy Press, New York.

Castellote, M.; Andrade, C.; Alonso, C. 2000. Electrochemical removal of chlorides. modelling of the extraction, resulting profiles and determination of the efficient time of treatment, Cement and Concrete Research 30: 615-621.

Castellote, M.; Llorente, I.; Andrade, C.; Turrillas, X.; Alonso, C.; Campo, J. 2006. Neutron diffraction as a tool to monitor the establishment of the electro-osmotic flux during realkalisation of carbonated concrete, Physica B, 385-386, 526-528. 
Kamaitis, Z. 2008. Modelling of corrosion protection for reinforced concrete structures with surface coatings, Journal of Civil Engineering and Management 14(4): 241-249.

Kubik, J. 1985. Thermodiffusion Flows in Solid with a Dominant Constituent, Mitteilungen aus dem Institut für Mechanik, Nr 44, Ruhr-Universität Bochum.

Mietz, J. 1998. Electrochemical Rehabilitation Methods for Reinforced Concrete Structures - A State of the Art Report: (EFC 24). Woodhead Publishing.

Miranda, J. M.; Gonzalez, J. A.; Cobo, A.; Otero, E. 2006. Several questions about electrochemical rehabilitation methods for reinforced concrete structures, Corrosion Science 48: 2172-2188.
Toumi, A.; François, R.; Alvarado, O. 2007. Experimental and numerical study of electrochemical chloride removal from brick and concrete specimens, Cement and Concrete Research 37(3): 54-62.

Wieczorek, G. 2002. Korozja zbrojenia inicjowana przez chlorki lub karbonatyzacje otuliny [Corrosion of the Reinforcement Initiated by Chlorides and Concrete Cover Carbonation], DWE, Wroclaw.

Yeih, W.; Chang, J. J. 2005. A study on the efficiency of electrochemical realkalisation of carbonated concrete, Construction and Building Materials 19: 516-524.

Zybura, A. 2007. Analysis of chloride migration in concrete based on multicomponent medium theory, Archives of Civil Engineering LIII, 1: 131-150.

\section{KARBONATIZAVUSIO BETONO ŠARMINĖS TERPĖS ATKŪRIMO MODELIS}

\section{Jaśniok, A. Zybura}

\section{$\mathrm{S}$ a n tra u a}

Karbonatizavusio betono šarminès terpès atkūrimo modelis sudarytas remiantis daugiakomponentès aplinkos teorijos lygtimis. Procesą aprašančios lygtys sudarytos atlikus masės balanso, elektros krūvio, judesio kiekio, energijos, taip pat entropijos nevienodumo parcialinių lygčių analizę. Eksperimentiniai tyrimai susieti su teoriniu modeliu apibrèžiant jonų koncentracijos pokyti tirpale apsauginio sluoksnio porose atkuriant šarminę terpę. Remiantis bandymu rezultatų analize, procesą aprašančios lygtys supaprastintos ir formaliai pertvarkytos i lygtis, aprašančias $\mathrm{OH}^{-}$jonų, susietų su Na+ jonais, pernešimu. Išsprendus ši uždavini atvirkštiniu keliu, išreikštas $\mathrm{OH}^{-}$jonų elektrodifuzijos koeficientas ir, remiantis eksperimentinių tyrimų rezultatais, nustatyta jo skaitinė reikšmė, sunkiai skaidomų tirpalų sritis, taip pat proceso nepastovumo itaka.

Reikšminiai žodžiai: betonas, armatūros korozija, elektrocheminis šarminės terpès atkūrimas, eksperimentiniai tyrimai, proceso modeliavimas.

Mariusz JAŚNIOK is PhD, MSc, CE at the Faculty of Civil Engineering at the Silesian University of Technology (Poland). His scientific interests concern the problems of concrete structure durability, especially methods of electrochemical concrete repair, and diagnostic methods of assessing corrosion conditions of concrete reinforcement.

Adam ZYBURA is Prof DSc, PhD, MSc, CE at the Silesian University of Technology (Poland). Head of the Department of Building Structures at the Faculty of Civil Engineering. His scientific interests concern the problems of the concrete structure durability. He specializes in the issue of the mathematical modelling the diffusion and electro-diffusion multicomponent flows, occurring in concrete, and in the diagnostic methods of assessing reinforcement steel corrosion conditions in concrete. 